\title{
Extra-Anatomic Urinary Drainage for Urinary Obstruction
}

\author{
Michael Kimuli, John Sciberras and Stuart Lloyd \\ St. James's University Hospital, Leeds \\ UK
}

\section{Introduction}

Long-term drainage of the urinary tracts of patients with impassable ureteric strictures remains a major challenge to the urologist. Until the mid 1970's the only viable, minimally invasive treatment was a permanent nephrostomy with all its sequelae, loss of quality of life, risk of tube dislocation, infection, and recurrent obstruction (Marberger, 2006). For decades, researchers experimented with different prosthetic ureteric replacements with minimal success. with minimal success. The breakthrough came in 1976 with a case report of the first successful prosthetic replacement of both ureters in a patient with malignant obstruction. The authors proved that not only were prosthetic materials possible replacements for ureters, peristaltic activity was not needed for permanent normal function of the upper urinary tract (Schulman, et al., 1976). This landmark study resulted in rapid progress in the investigation for potential materials for ureteric replacement that could be used without need for major reconstructive surgery. However, it was not until 1994 that the first viable 7F double-pigtail prosthetic extra-anatomic bypass system was developed (Lingam et al., 1994). Despite several series reporting excellent outcomes during the last two decades, extraanatomic stenting is not yet universally offered to candidate patients.

Conventionally, such patients are offered a minimally invasive procedure in the form of a percutaneous nephrostomy or alternatively reconstructive surgery. Percutaneous nephrostomy, though minimally invasive, is far from ideal for long-term use. Reconstructive surgery overcomes some of the problems related to long-term nephrostomy use; however, it requires patients to undergo major surgery. Unfortunately, the majority of impassable ureteric strictures are due to malignant disease, which has been reported to carry a poor prognosis with a resulting median survival of 3 to 7 months (Kouba et al., 2008). This prognosis highlights the importance of maintaining quality of life in this group of patients and major reconstructive surgery with all its potential sequelae, should ideally be avoided.

An ideal urinary diversion should provide symptomatic relief for the required duration without requiring multiple changes and should be associated with minimal or no morbidity. Several authors have reported their experience of using extra-anatomical stents (EAS) for temporary or permanent drainage of obstructed urinary tracts (Ahmadzadeh, 1991; Lingam et al., 1994; Nakada et al., 1995; Desgrandchamps et al., 1998a 1998b; Minhas et al., 1999; Lloyd et al., 2007). In this chapter, we describe the indications for and the technique of inserting the EAS, and a review of the results from the major series. 


\section{Patient indications}

The main indication for insertion of an EAS is malignant ureteric obstruction that has failed management with internal ureteric stenting or nephrostomy (Fig 1a-b). Patients with benign ureteric obstruction that have either failed open reconstructive surgery or are unfit or unwilling to undergo open surgery can also be considered for EAS. Increasing experience with EAS has been paralleled by an expansion in it is indications. At our institution for example, we have successfully used EAS to treat intractable urinary incontinence due to ureteric fistulae in patients otherwise unfit for open surgical repair. In some patients, it has been used as a temporary measure for ureteric fistula before definitive repair is carried out. Lastly, EAS is increasingly being used in transplanted kidneys (Olsburgh , 2007) as well as in patients with ileal conduit (own series).

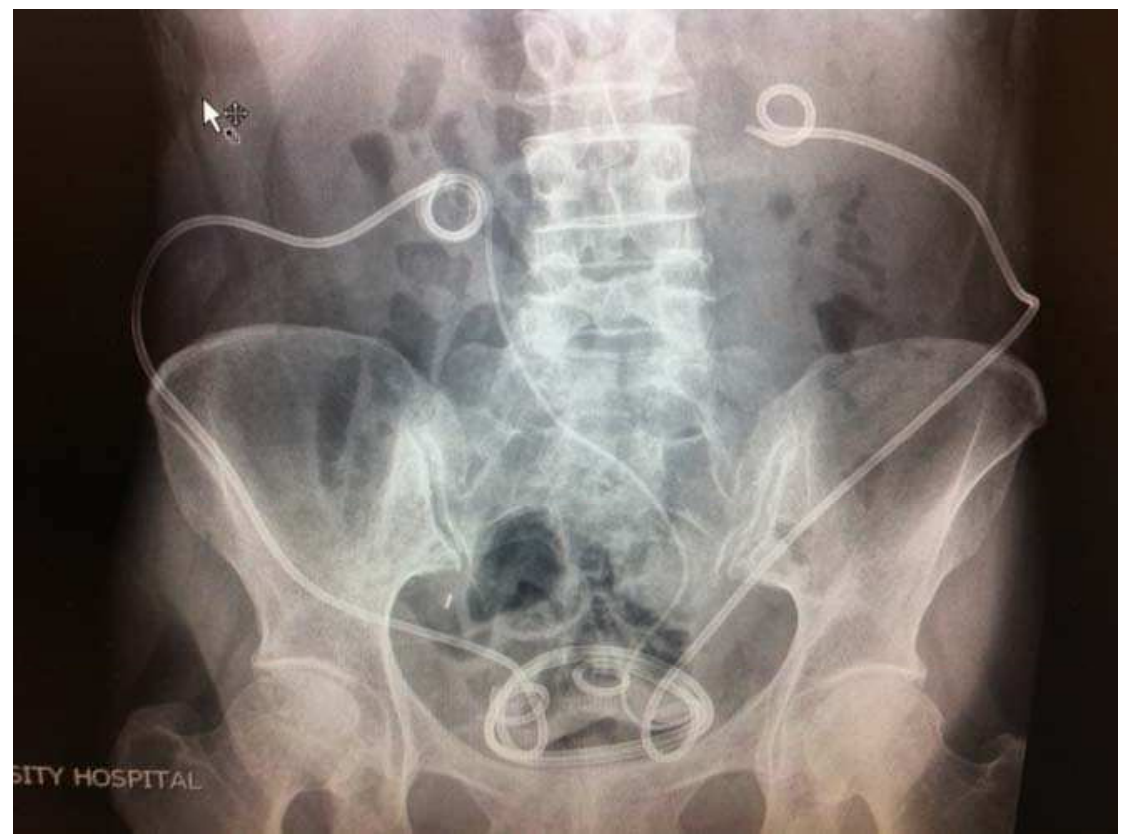

Fig. 1a. Bilateral Extra-anatomic stents of the Paterson Forrester type (short-term). There is also trans-ureteric ureterostomy stent seen in-situ to be removed. Patient had bilateral strictures and fistula after reconstruction in a post-irradiated abdomen and several attempts at corrective surgery without success.

The only absolute contraindications are uncorrected coagulopathies and active malignancy, either arising or invading the bladder. Tumour seeding along the track may occur if the stent is placed near a tumour (Fig. 2). Bowel stomas and multiple abdominal scars make stent placement more challenging but are not a contraindication. Likewise, patients with a small capacity bladder require appropriate counseling regarding potential increased urinary frequency especially if they have been managed with nephrostomy for a long time. Patients should be warned of the risk of subcutaneous infection that will usually respond to a course of appropriate antibiotic. Rarely, the infection may necessitate removal of the stent with a 


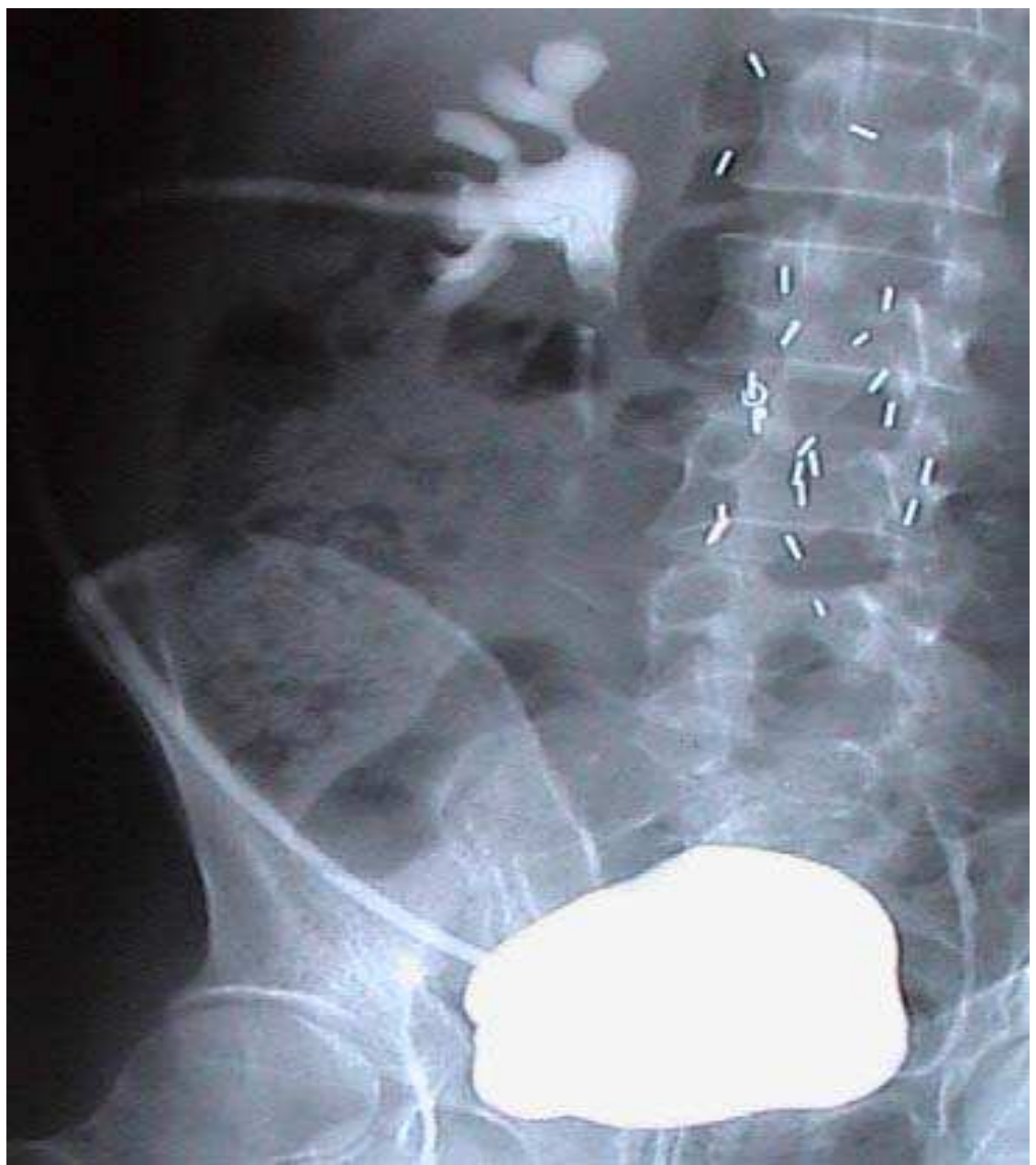

Fig. 1b. Cystogram in a patient with a Detour extra-anatomic stent (permanent type) for ureteric obstruction after sarcoma excision.

temporary conversion of the proximal end to a nephrostomy. Rarely still, stent blockage may occur requiring change before 12 months. In our experience, storage bladder symptoms from the stent are exceptionally rare and no stent was ever removed at our institution due to this problem.

\section{Stents}

Different types of EAS have been developed and used successfully by different authors (Lingam, 1994; Minhas, 1999; Desgrandchamps, 1998a; Lloyd, 2007). The designs have varied with the materials used, length of stent, diameter of stent and on whether one or composite stent/s are utilized. They however, all have a common objective of establishing a 


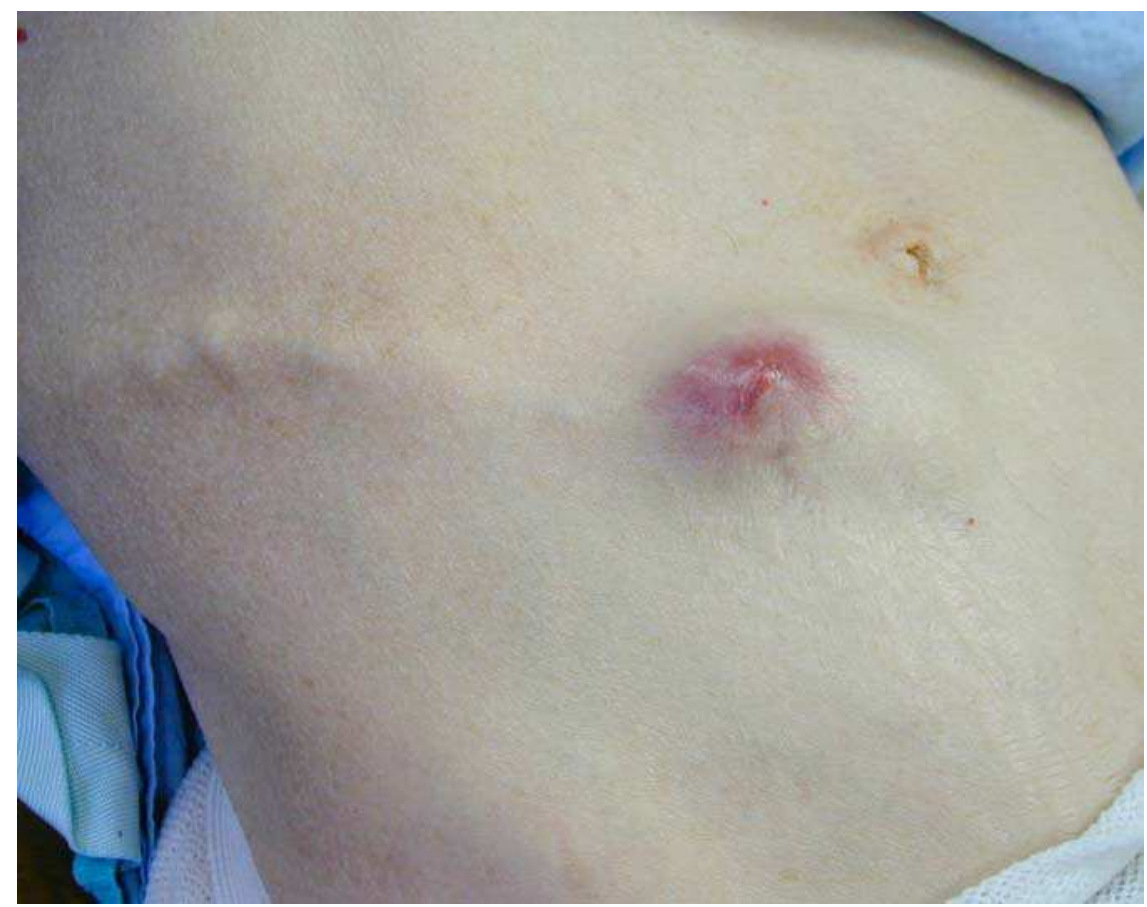

Fig. 2. Tumour invasion along the route of an extra-anatomic stent.

nephro-vesical subcutaneous urinary diversion. The diameter of the stent is thought to be the main determinant of the duration the stent may remain in situ without encrustation or blocking. It has been estimated that a $17 \mathrm{~F}$ diameter is required to prevent stent encrustation irrespective of its composition in association with increased fluid intake (Andonian, et al. 2005).

To this end, we utilize two types of stents in our practice. One is a short-term $8.5 \mathrm{~F} 65 \mathrm{~cm}$ EAS without side holes except at either end. We offer to all patients with malignant disease and in patients with poor general health and benign disease where there is concern regarding the functionality of the bladder. If they survive the first change and have a good prognosis, we will usually discuss conversion to a more long-term 29F Detour EAS. The latter stent requires a more invasive technique including an open cystostomy but has the advantage of potentially being a permanent diversion with a single procedure. We use it as a primary option in patients with a long life expectancy. Below, we describe our technique of inserting both types of stents.

\section{The Paterson-Forrester stent}

\subsection{Equipment}

The Paterson-Forrester $65 \mathrm{~cm}, 8.5 \mathrm{~F}$ polyurethane stent (Cook Ireland Ltd)

Cystoscopy tray for either (flexible or rigid cystoscopy) 
Percutaneous nephrostomy track placement tray with telescopic metal dilators to size $3(18 \mathrm{~F})$.

Contrast solution in a luer lock syringe

Minor operation tray with scalpel, tissue forceps and clips

Dissecting scissors

Needle holder and absorbable sutures

Nephrostomy needle and $0.38 \mathrm{~F}$ j tip wire

12 F peel away sheath

0.38F floppy tip stiff core Sensor wire (Microvasive)

Extra equipment for exchange of stent

$6 \mathrm{~F}$ end flushing ureteric catheter

Flexible rat-toothed stent removing forceps if flexible cystoscope is used

\subsection{First time insertion PF stent}

The procedure for insertion involves three steps:

1. Insertion of stent in the kidney via a new or existing nephrostomy tract. Our preferred option is to use the track of an existing nephrostomy tube after a minimum of 5 days insertion.

2. Creation of a subcutaneous tunnel and tunneling of the stent to reach the supra-pubic region.

3. Creation of a supra-pubic tube cystostomy and insertion into the bladder in the bladder.

Step 1

For unilateral placement, the patient is positioned in the Lloyd-Davis position, with the ipsilateral leg in extension and the affected side elevated to approximately $20^{\circ}$ with 3 litre saline bags. Gram-negative antibiotic prophylaxis is given - usually Gentamicin $2 \mathrm{mg} / \mathrm{Kg}$. The skin is prepared with aqueous iodine and draping applied to leave the abdomen and nephrostomy tube exposed (Fig. 3). The C-arm is positioned at the opposite side of the stent insertion while the camera with stack is placed near the foot of the table opposite the operator. An assistant needs to be able to perform a cystoscopy at the same time the operator places the upper end of the stent as detailed below.

Ideally the patient already has a nephrostomy tube in place and thus the following steps are undertaken. However, it is possible to create a new track and deliver the proximal end of the stent into the kidney de-novo. Local anaesthetic is injected into the skin around the nephrostomy tube and contrast is injected to opacify the collecting system. A 0.38 F Sensor guide wire (Microvasive) is passed through the existing nephrostomy tube and the tube removed under screening leaving the wire in the system. The tapered end of the EAS is placed into the collecting system over the wire producing a good coil in the kidney. The skin incision is extended in a transverse direction for $2 \mathrm{~cm}$ and the existing cutaneous aspect of the existing fistulous track is excised and dissected free from the rest of the tract in order to allow the stent to sit below the skin cutaneous margin (Fig. 4). 


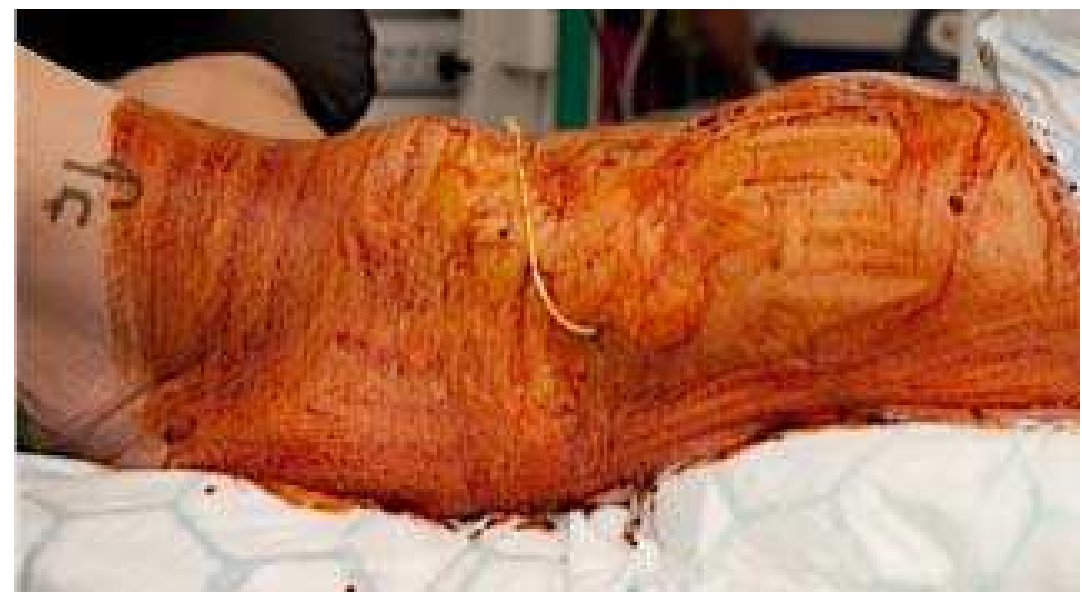

Fig. 3. Patient positioning over the edge of the operating table with fluid bags elevating the side and the nephrostomy tube included in skin preparation.

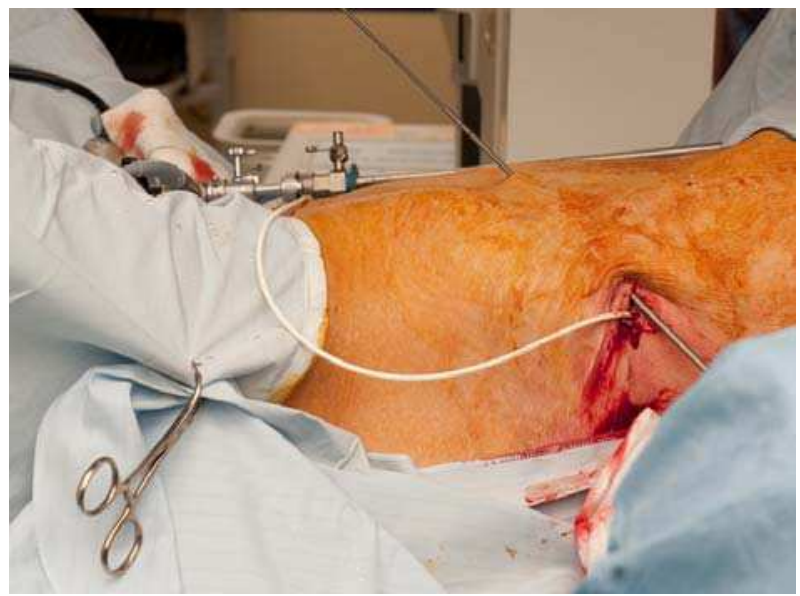

Fig. 4. The Paterson-Forrester extra-anatomic stent is passed over a guide wire and replaces the nephrostomy tube. The skin bridge is dissected free.

\section{Step 2}

The Alken PCNL coaxial metal dilators are used to create a multi-stage subcutaneous tunnel (Fig. 5). The 9F long metal guide rod is passed in the subcutaneous fat layer obliquely towards the iliac fossa. The tract is sequentially dilated to $18 \mathrm{~F}$. After injection with local anaesthetic the skin is incised over the tip of the dilators at a point that allows control of both ends of the dilators. The smaller dilators are retrieved from the new incision leaving only the $18 \mathrm{~F}$ dilator in place through which the EAS is passed towards the bladder. The metal dilator is then retrieved distally leaving the stent in a new subcutaneous tunnel. The procedure is repeated two or three times depending upon the route taken to the supra-pubic area avoiding scars and or stomas. 


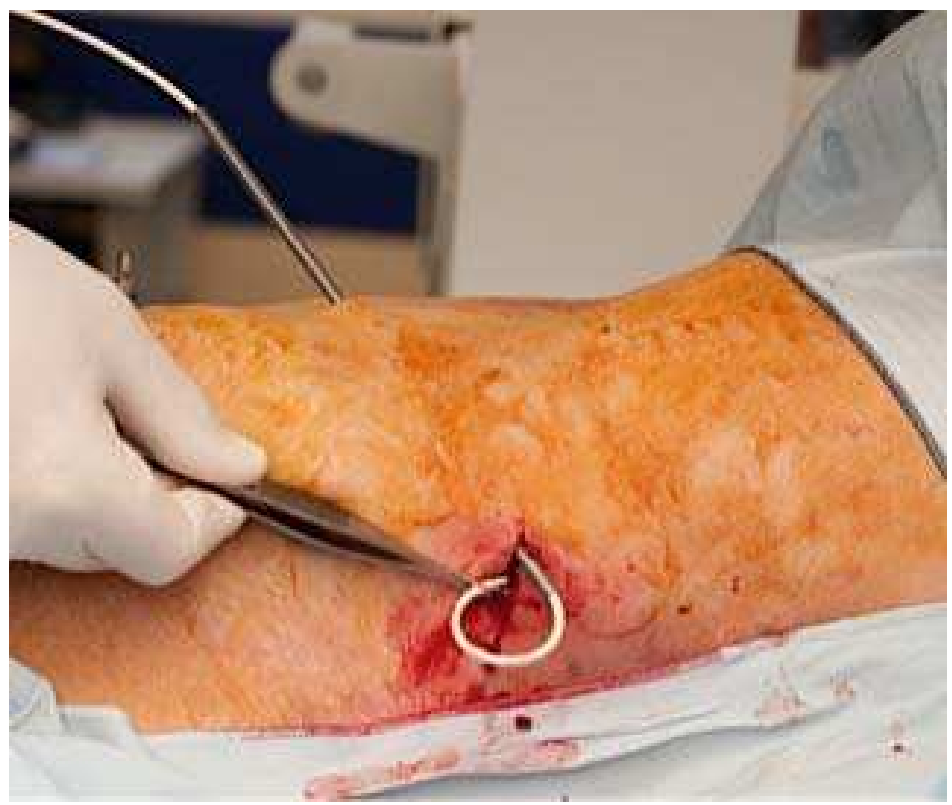

Fig. 5. The Alken dilators used to create a subcutaneous tunnel down to the supra-pubic region.

\section{Step 3}

The site of the last skin incision should be in the supra-pubic region but lateral to the midline. An assistant performs a cystoscopy to allow visualization of the stent as it is inserted into the bladder using a modified Seldinger technique with the aid of a $12 \mathrm{~F}$ peelaway sheath. Before the stent is finally delivered into its final subcutaneous tunnel the position of proximal end of the stent is checked with $x$ ray screening (Fig. 6). The presence of a cystoscope should prevent distal stent migration out through the urethra. The skin is closed with absorbable sutures and skin glue.

\subsection{Exchange of PF stent}

Stents are changed routinely at 12 months (although licensed for 3 months), using the following technique:

A clip is used to identify a suitable position to incise the skin anteriorly, ideally half way along the stent but any position proximal to the bladder is acceptable. It is better to be able to see this site and the proximal coil in the kidney in the same fluoroscopic image. Making a small transverse incision at the appropriate site exposes the stent. The stent is then cut and a Sensor guide-wire passed through the proximal portion of the stent, which is then removed. The new stent is passed over the guide-wire before withdrawing the wire. The guide-wire is then passed into the bladder via the distal end of the old stent, which is then removed. The distal end of the new stent is passed over the wire into the bladder and the guide-wire removed endoscopically from the distal end of the stent (Minhas et al., 1999). 


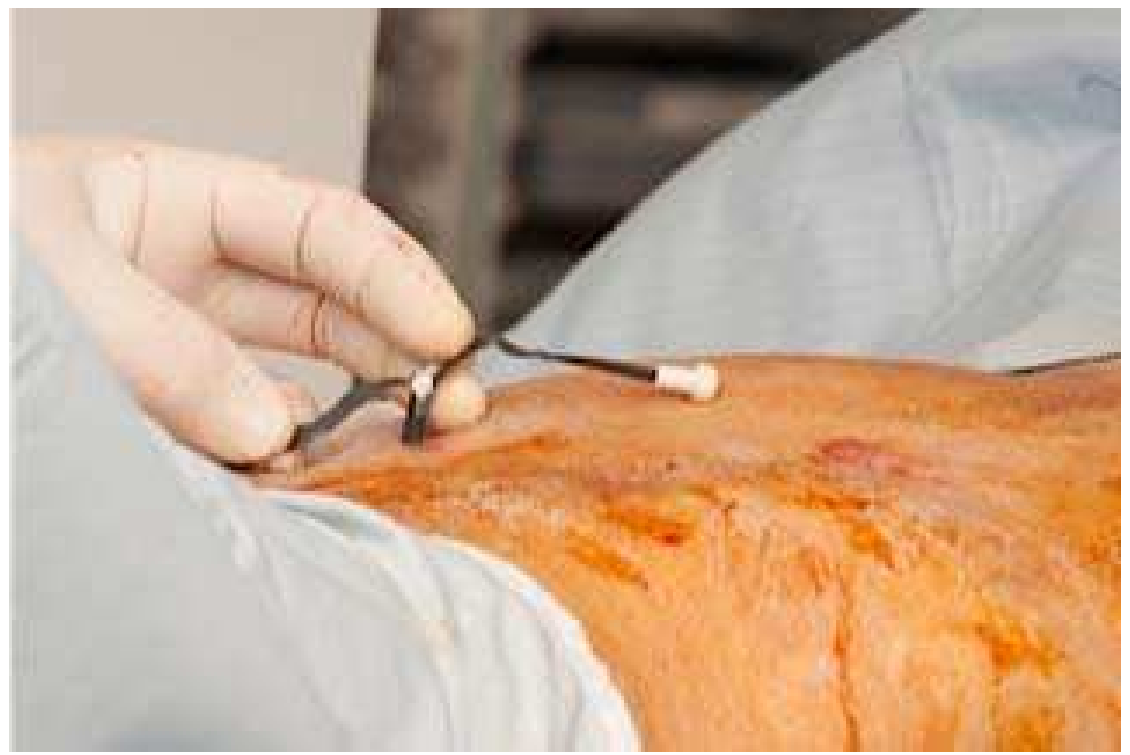

Fig. 6. Supra-pubic puncture and peel-away sheath used to deliver stent into the bladder under cystoscopic control.

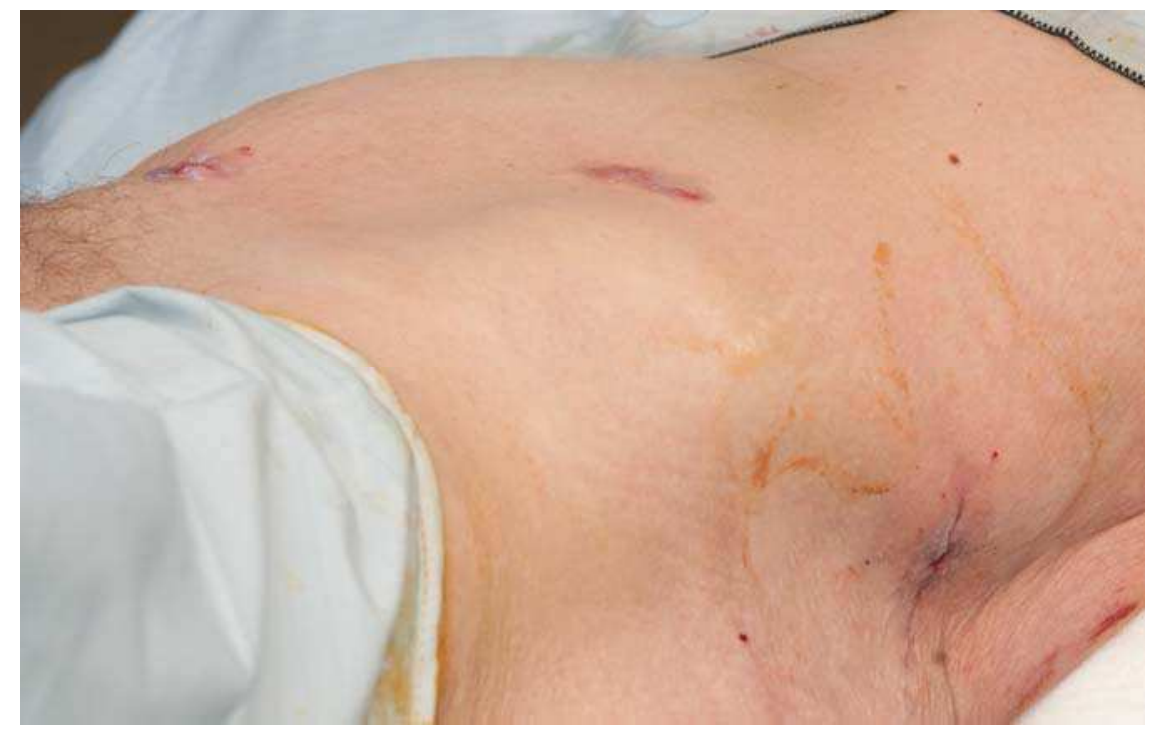

Fig. 7. Wounds closed with subcutaneous absorbable sutures and skin glue.

\section{Insertion of the detour stent}

The equipment required are provided as a kit and include the 29F PTFE-silicone stent and the dilator (Coloplast, UK). In addition, a surgical set suitable for a lower abdominal 
transverse incision is required. Insertion of the permanent Detour stent follows the same principals described above but because it is a bigger stent $(29 \mathrm{~F})$, it requires the tract to be dilated to 30F (Lloyd et al., 2007). This is achieved with a 30F renal Amplatz sheath and a large-bore plastic subcutaneous tunneling device, which are included in the kit (Fig. 8a-f). A lower abdominal transverse incision is undertaken before a $1 \mathrm{~cm}$ open cystostomy is performed via which the stent is placed into the bladder and secured with 4-0 Vicryl sutures to the bladder serosa. The large bore subcutaneous stent can be easily palpated and seen in the thin patient (Fig. 9).

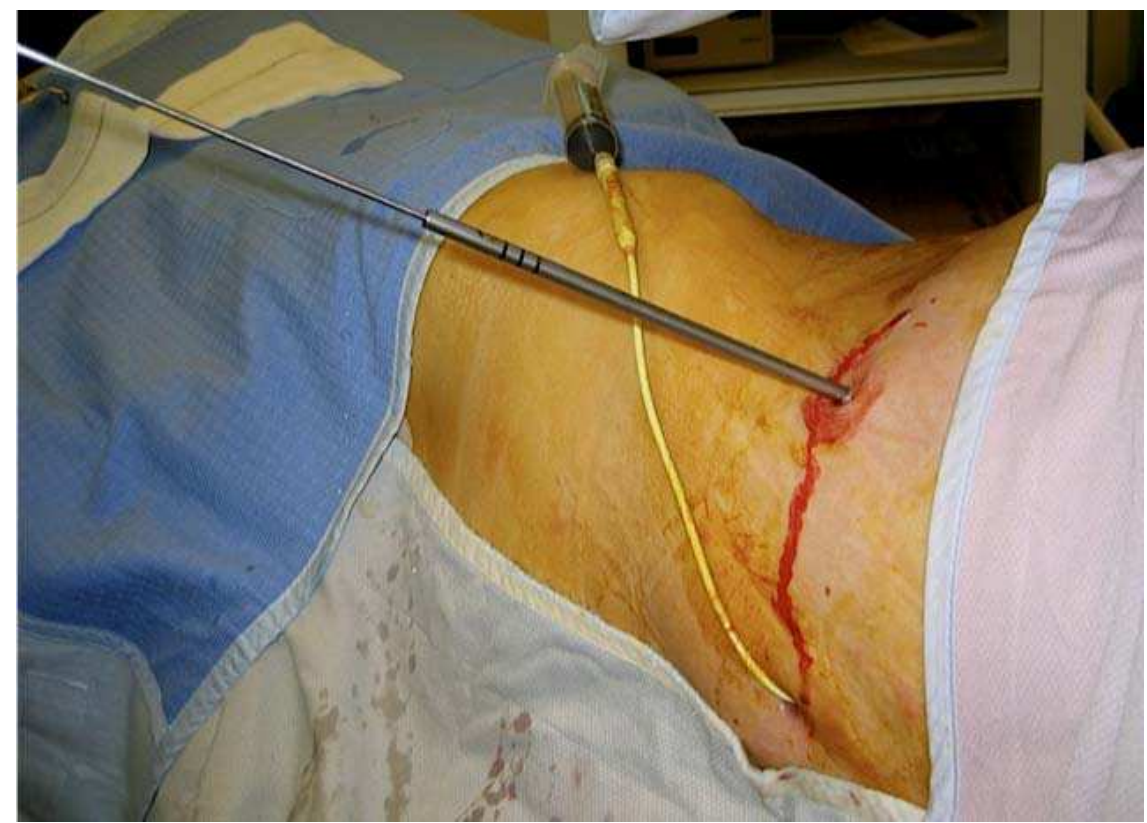

Fig. 8a. Lateral percutaneous track using the existing nephrostomy to inject contrast to outline and dilate the pelvi-calyceal system

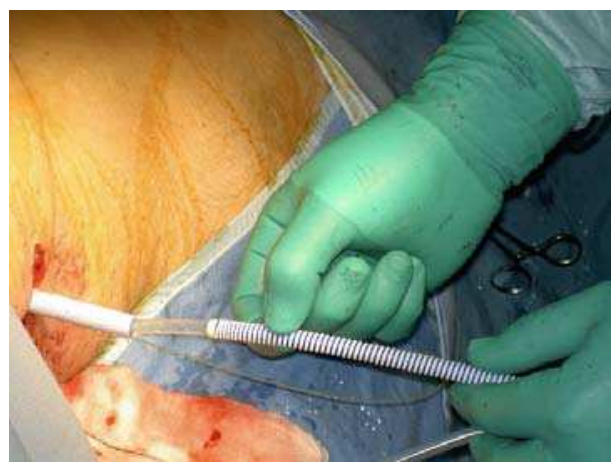

Fig. $8 \mathrm{~b}$. Insertion of the proximal end of the Detour stent through the Amplatz sheath into the kidney (note yellow radiolucent ring to aid positioning). 


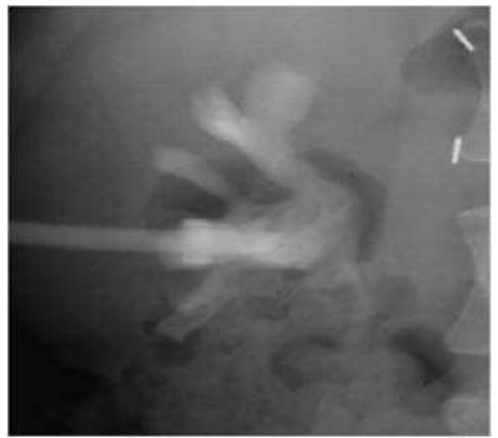

Fig. 8c. Opaque contrast medium injected through the stent to ensure correct positioning.

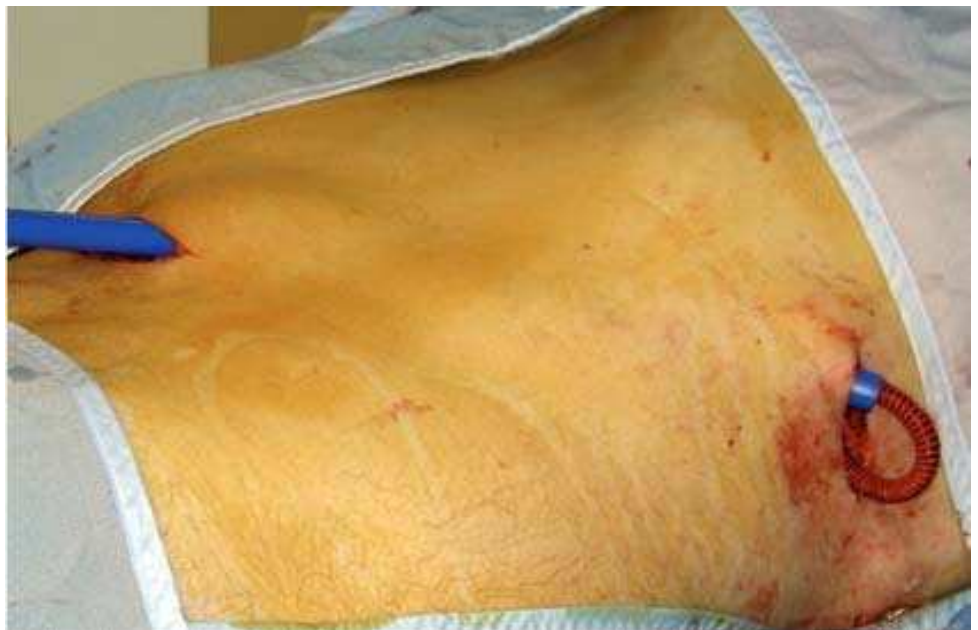

Fig. 8d. Subcutaneous tunneling device (blue) and Detour stent being positioned from renal puncture site to supra-pubic region prior to bladder suture

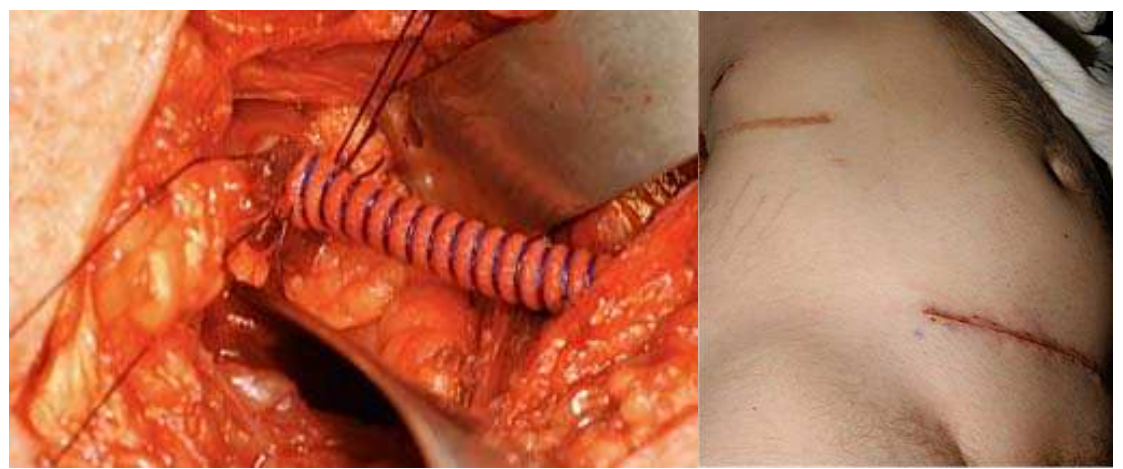

Fig. 8e,f. Sutured cystostomy after shortening the stent, skin glue is applied to wounds after subcutaneouse sutures and glue. 


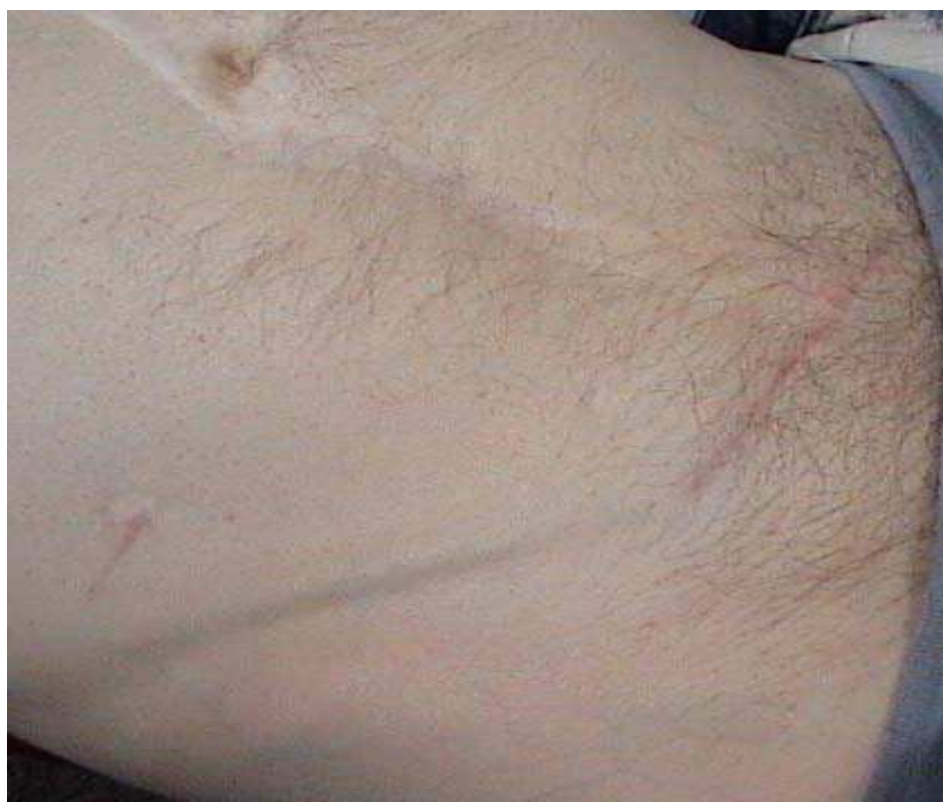

Fig. 9. Wide bore Detour stent may be palpable in thin patients. Healed incisions are visible.

\section{Post-operative management and follow-up}

A Foley catheter may be left in the bladder for a few hours to observe fluid balance but it is not essential following insertion of the short term EAS. Patients are usually discharged home on the day of surgery or the following day. The referring physician monitors the renal function. The patients are instructed to seek medical help immediately if they develop any signs of local or systemic sepsis. Following placement of the Detour stent, an indwelling catheter is left in situ for 1 week, and a cystogram is performed to check the integrity of the suture line before catheter removal (Fig. 10). Flexible cystoscopic view may show some mucosal oedema at the site of implantation (Fig. 11). 


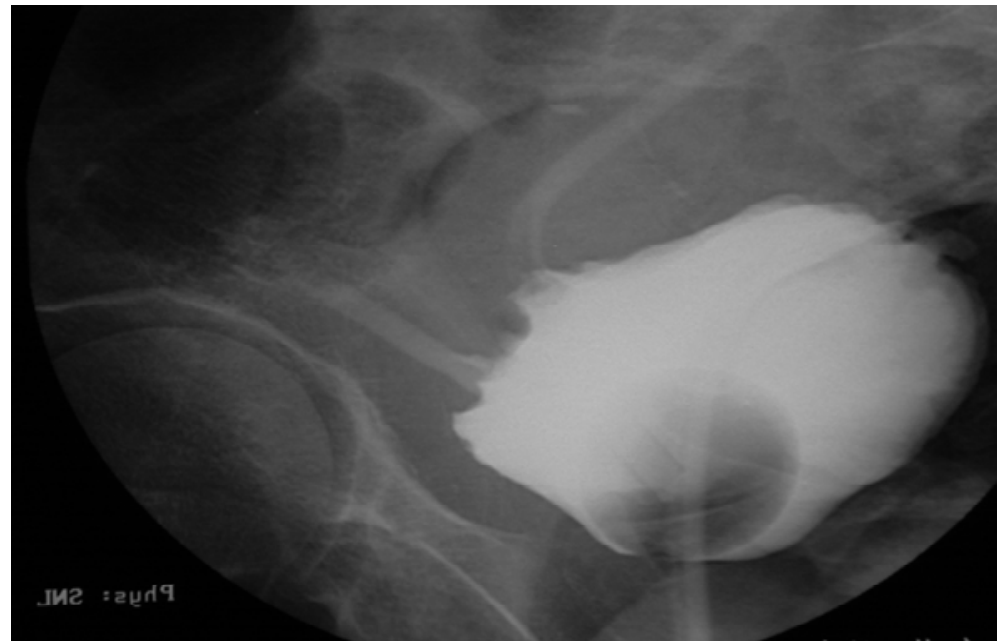

Fig. 10. Cystogram used to check for suture line integrity.

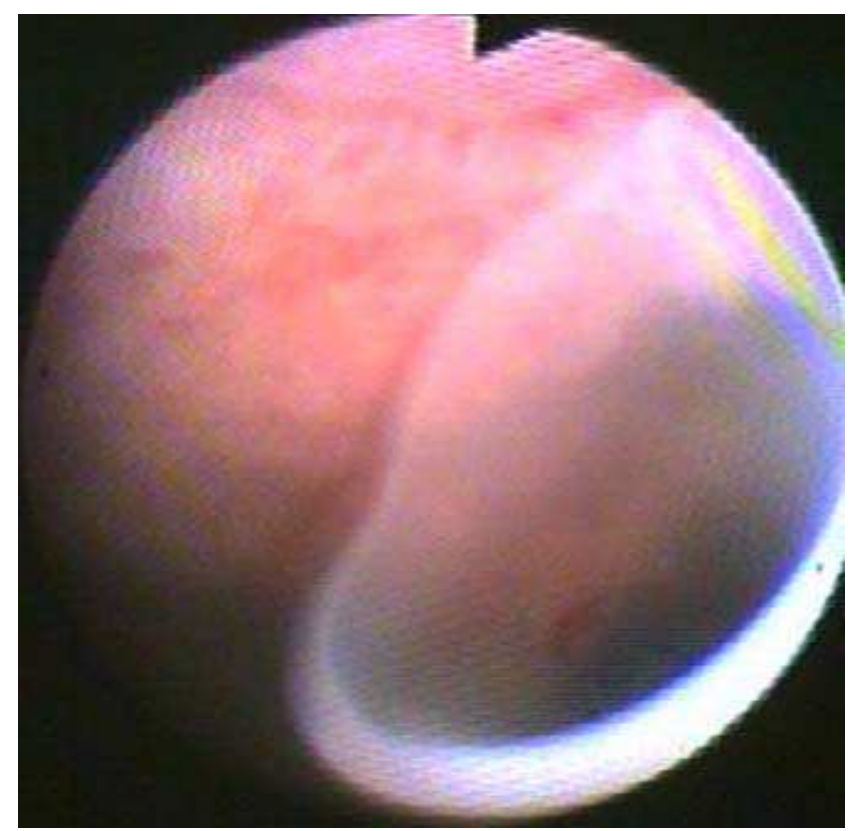

Fig. 11. Cystoscopic appearance of the silicone part of the Detour stent.

\section{Discussion of results}

End-stage ureteric obstruction, which has failed ureteric stenting, presents a significant challenge the urologist. Most of our patients have terminal cancer and are therefore not ideal 
candidates for major reconstructive surgery. The remainder of the patients have either failed or declined reconstructive surgery, or are too frail for major surgery. The conventional practice of managing this group of patients is with external percutaneous nephrostomy drainage. Unfortunately long-term nephrostomy drainage presents significant compromises to the patient's quality of life in addition to requiring regular changes.

In 1991, Ahmadzadeh reported short-term results in 8 patients with ureteric obstruction who underwent subcutaneous urinary diversion using a specially designed stent. The procedure had the advantage of being simple whilst at the same time avoided the complications and social effects of other methods of palliative treatment by urinary diversion (Ahmadzadeh 1991). Since this pioneering article, several authors have reported their experience with different types of EAS for urinary diversion. In 1994 Lingam and colleagues reported their series of 5 patients who had EASs inserted during a 15-month period. The diversion was created using a specially designed 7F double pigtail stent, which they routinely changed at 4-month intervals. They found it to be a safe, effective and an acceptable alternative to nephrostomy drainage that improved quality of life (Lingam et al., 1994). A year later, another small study reported a marked improvement in patients' overall comfort and quality of life following conversion of nephrostomies to EASs using a similar but slightly larger 8.5F stent (Nakada et al., 1995). In the same year, Desgrandchamps introduced another stent prototype, which was a one-piece, self-retaining expanded polytetrafluoroethylene-silicone tube that was successfully assembled as an EAS in 19 patients with a mean follow-up of 7.2 months. All patients expressed an improvement in the quality of life although in one case, a conversion to a conventional percutaneous nephrostomy was necessary (Desgrandchamps et al., 1995).

In 1999, our group published results of 13 patients treated with EAS. Urinary diversion was successful in all patients; two survived for more than 1 year, with changes at six monthly intervals. In three patients the stents were replaced by percutaneous nephrostomies because of problems with leakage or infection. The remaining patients died with functioning EAS in situ. For the first time long-term follow up was reported. This study showed that the mean (range) time from stent placement to death was 7.5 (3-18) months. It was also the first time in the literature that an EAS had been used in a patient with a benign stricture of a native ureter. The patient remained well and was alive to the end of the study at 24 months (Minhas et al., 1999). Since this original publication, we have implanted over one hundred EAS in candidate patients at our institution with equally excellent results (unpublished series).

One drawback of this one-piece stent was its long length of 70-cm, which some found to be complex to implant, time-consuming, and cumbersome for the patient (Schmidbauer et al., 2006). Nissenkorn and Gdor developed a two $14 \mathrm{~F} 50-\mathrm{cm}$ polyurethane J stents joined by a connector. After stent placement was confirmed by injecting a contrast agent through the tube, the stents were intra-operatively shortened as needed before linking them together. They used the stents successfully in eight patients with a mean follow up of mean 5.5 months (Nissenkorn \& Gdor, 2000). In 2006, Schmidbauer et al. reported their successful results using a composite prosthesis set composed of two $12 \mathrm{~F}$ polyurethane J-tubes, a 58 -cm percutaneous nephrostomy part and a $56-\mathrm{cm}$ percutaneous cystostomy part, malleable tunnelers, and a metal connector for joining the two tubes. In 27 patients followed up for 12 months $(2-54$ months) an improvement in mean quality of life score from $3.4+/-1.4$ pre-operatively to $7.6+/-$ 
1.0 post-operatively was reported. In five patients (17.9\%) the system had to be replaced due to occlusion at a mean follow-up of 10.2 months. In three out of these five patients only the distal part of the two-piece bypass was exchanged (Schmidbauer et al., 2006).

Desgrandchamps et al. were the first authors to report use of a permanent PTFE-silicone EAS (Detour). They reported 3 patients who underwent successful EAS for ureteric necrosis, a rare complication of renal transplantation (Desgrandchamps et al., 1998). In 2001, the same group, reported use of the PTFE-silicone EAS in 27 patients with neoplastic (22) or benign (5) ureteric strictures. The mean follow-up was 6.3 months for the deceased patients and 47 months for the surviving ones, the longest follow-up being 84 months. In 3 cases, the EAS had to be removed due skin erosion in one and local tumour progression with bladder fistulae in two patients. Otherwise, five patients survived with the prosthesis in situ and a follow-up as long as 84 months without encrustation, infection, obstruction, or skin problems and with normally functioning kidneys (Jabbour et al., 2001). A prospective evaluation of their patients' quality using the EORTC QLC-30 questionnaire following insertion of the Detour EAS demonstrated an improvement of the function scale as a result of the elimination of the external percutaneous tube and a parallel worsening of the symptom scale secondary to the progression of disease (http://groups.eortc.be/qol/ questionnaires_qlqc30.htm). Patient ratings of the global quality of life and satisfaction with the urinary diversion were high because of the absence of the percutaneous tube (Desgrandchamps et al., 2007). Other authors have since reported equally excellent results with the Detour EAS (Lloyd et al., 2007; Olsburgh et al., 2007; Burgos et al., 2009).

Aminsharifi A et al. recently described a promising simple modification of using percutaneous access to the bladder utilizing a split Amplatz sheath, and thus obviating the need for open cystostomy incision (Aminsharifi et al., 2010).

The main long-term complication reported is tumour invasion along the stent and active bladder cancer is the main contraindication to EAS insertion. One case report reported a patient presenting with acute obstruction of the Detour system secondary to a Candida infection that was managed successfully with short term nephrostomy and systemic antimycotic therapy without removing the stent (Bynens et al., 2006).

\section{Conclusion}

The long term data show that EAS offers an excellent temporary or permanent internalization of urinary drainage with a minimally invasive method where open surgery has been tried and failed or was not considered feasible, and avoids the need for long-term nephrostomy drainage.

An ideal EAS should be associated with minimal or no peri-operative morbidity; whilst at the same time does not require regular changes. Such a stent does not currently exist but it is likely that the rapid advancement in tissue engineering and biomaterials will make it possible to design one soon.

\section{References}

Ahmadzadeh, M. (1991). Clinical experience with subcutaneous urinary diversion: new approach using a double pigtail stent. Br J Urol, 67, 596-599. 
Aminsharifi, A., Taddayun, A., Jafari, M. \& Ghanbarifard, E. (2010). Pyelovesical bypass graft for palliative management of malignant ureteric obstruction: optimizing the technique by percutaneous access to the bladder using a split Amplatz sheath. Urology, 76, 993-995.

Andonian, S., Zorn, K.C., Paraskevas, S. \& Anidjar, M. (2005). Artificial ureters in renal transplantation. Urology, 66, 1109.

Burgos, F.J., Bueno, G., Gonzalez, R., Vazquez, J.J., Diez-Nicolas, V., Marcen, R., Fernandez, A. \& Pascual, J. (2009). Endourologic implants to treat complex ureteral stenosis after kidney transplantation. Transplant Proc, 41, 2427-2429.

Bynens, B.G., Ampe, J.F., Denys, H. \& Oyen, P.M. (2006). Case report: relief of acute obstruction of the Detour subcutaneous pyelovesical bypass. J Endourol, 20, 669-671.

Desgrandchamps, F., Cussenot, O., Meria, P., Cortesse, A., Teillac, P. \& Le Duc, A. (1995). Subcutaneous urinary diversions for palliative treatment of pelvic malignancies. $J$ Urol, 154, 367-370.

Desgrandchamps, F., Duboust, A., Teillac, P., Idatte, J.M. \& Le Duc, A. (1998a). Total ureteral replacement by subcutaneous pyelovesical bypass in ureteral necrosis after renal transplantation. Transpl Int, 11 Suppl 1, S150-151.

Desgrandchamps, F., Leroux, S., Ravery, V., Bochereau, G., Menut, P., Meria, P., Ballanger, P. \& Teillac, P. (2007). Subcutaneous pyelovesical bypass as replacement for standard percutaneous nephrostomy for palliative urinary diversion: prospective evaluation of patient's quality of life. J Endourol, 21, 173-176.

Desgrandchamps, F., Paulhac, P., Fornairon, S., De Kerviller, E., Duboust, A., Teillac, P. \& Le Duc, A. (1998b). Artificial ureteral replacement for ureteral necrosis after renal transplantation: report of 3 cases. J Urol, 159, 1830-1832.

Jabbour, M.E., Desgrandchamps, F., Angelescu, E., Teillac, P. \& Le Duc, A. (2001). Percutaneous implantation of subcutaneous prosthetic ureters: long-term outcome. J Endourol, 15, 611-614.

Kouba, E., Wallen, E.M. \& Pruthi, R.S. (2008). Management of ureteral obstruction due to advanced malignancy: optimizing therapeutic and palliative outcomes. J Urol, 180, 444-450.

Lingam, K., Paterson, P.J., Lingam, M.K., Buckley, J.F. \& Forrester, A. (1994). Subcutaneous urinary diversion: an alternative to percutaneous nephrostomy. J Urol, 152, 70-72.

Lloyd, S.N., Tirukonda, P., Biyani, C.S., Wah, T.M. \& Irving, H.C. (2007). The detour extraanatomic stent--a permanent solution for benign and malignant ureteric obstruction? Eur Urol, 52, 193-198.

Marberger, M. 2006. Prosthetic nephrovesical bypass. Eur Urol, 50, 879-883.

Minhas, S., Irving, H.C., Lloyd, S.N., Eardley, I., Browning, A.J. \& Joyce, A.D. (1999). Extraanatomic stents in ureteric obstruction: experience and complications. BJU Int, 84, $762-764$.

Nakada, S.Y., Gerber, A.J., Wolf, J.S., Jr., Hicks, M.E., Picus, D. \& Clayman, R.V.(1995). Subcutaneous urinary diversion utilizing a nephrovesical stent: a superior alternative to long-term external drainage? Urology, 45, 538-541.

Nissenkorn, I. \& Gdor, Y. (2000). Nephrovesical subcutaneous stent: an alternative to permanent nephrostomy. J Urol, 163, 528-530.

Olsburgh, J., Dorling, A., Tait, P. \& Williams, G. (2007). Extra-anatomic stents for transplant ureteric stenosis. Br J Radiol, 80, 216-218. 
Schmidbauer, J., Kratzik, C., Klingler, H.C., Remzi, M., Lackner, J. \& Marberger, M. (2006). Nephrovesical subcutaneous ureteric bypass: long-term results in patients with advanced metastatic disease-improvement of renal function and quality of life. Eur Urol, 50, 1073-1078.

Schulman, C.C., Vandendris, M., Vanlanduyt, P. \& Abramow, M. (1976). Total replacement of both ureters by prostheses. Eur Urol, 2, 89-91. 


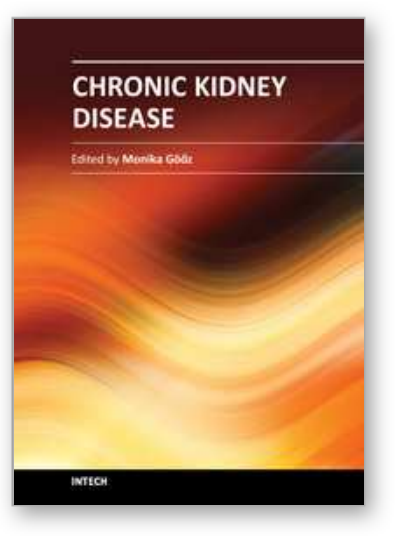

\author{
Chronic Kidney Disease \\ Edited by Prof. Monika Göőz
}

ISBN 978-953-51-0171-0

Hard cover, 444 pages

Publisher InTech

Published online 16, March, 2012

Published in print edition March, 2012

Chronic kidney disease is an increasing health and economical problem in our world. Obesity and diabetes mellitus, the two most common cause of CKD, are becoming epidemic in our societies. Education on healthy lifestyle and diet is becoming more and more important for reducing the number of type 2 diabetics and patients with hypertension. Education of our patients is also crucial for successful maintenance therapy. There are, however, certain other factors leading to CKD, for instance the genetic predisposition in the case of polycystic kidney disease or type 1 diabetes, where education alone is not enough.

\title{
How to reference
}

In order to correctly reference this scholarly work, feel free to copy and paste the following:

Michael Kimuli, John Sciberras and Stuart Lloyd (2012). Extra-Anatomic Urinary Drainage for Urinary Obstruction, Chronic Kidney Disease, Prof. Monika Göőz (Ed.), ISBN: 978-953-51-0171-0, InTech, Available from: http://www.intechopen.com/books/chronic-kidney-disease/extra-anatomic-urinary-drainage-for-urinaryobstruction

\section{INTECH}

open science | open minds

\section{InTech Europe}

University Campus STeP Ri

Slavka Krautzeka 83/A

51000 Rijeka, Croatia

Phone: +385 (51) 770447

Fax: +385 (51) 686166

www.intechopen.com

\section{InTech China}

Unit 405, Office Block, Hotel Equatorial Shanghai

No.65, Yan An Road (West), Shanghai, 200040, China

中国上海市延安西路65号上海国际贵都大饭店办公楼 405 单元

Phone: +86-21-62489820

Fax: $+86-21-62489821$ 
(C) 2012 The Author(s). Licensee IntechOpen. This is an open access article distributed under the terms of the Creative Commons Attribution 3.0 License, which permits unrestricted use, distribution, and reproduction in any medium, provided the original work is properly cited. 